\title{
WHAT'S A NINE LETTER WORD FOR “A TYPE OF WORD PUZZLE"?
}

\section{James Little}

Although the crossword puzzle is a common element of the language teacher's repertoire, it is still a relatively recent development. Englishborn Arthur Wynne, a compiler of word squares, anagrams and other word puzzles, can be credited with introducing the crossword in both the U.S., and later, England. When his "Wordcross" puzzle first appeared on December 21, 1913 in the New York World, Wynne had no idea how popular this feature would become. For ten years, the World was the only newspaper to run crosswords. They were introduced in Britain in 1924, when one of Wynne's crosswords appeared in the Sunday Express. This was also the same year that the first crossword puzzle book was published by Simon and Schuster. They too had little inkling of how successful this kind of book would be.

Crossword puzzles have two historical antecedents: acrostics and word squares. Acrostics date from the time of the ancient Greeks; they often appear in verse. In the standard version, the initial letters in each line spell a word when read down. Psalm 119 in the Old Testament is an early example of an acrostic which spells the Hebrew alphabet. Word squares are also ancient, dating from the Roman era. In a word square, a list of words appears that can be read both vertically and horizontally. An example of a word square was found in the ruins of Pompeii, and is dated 79 A.D. Both word squares and acrostics were popular up to Victorian times. In the 19th century, word squares with clues began to appear in popular magazines in England. What Wynne did was to combine features of both the acrostic and word square to make his "Word-cross".

Millington (1977), who provides this fascinating history, also mentions that there was an educational interest in crosswords as early as the 1920s. For the first language, they were seen as a valuable tool in developing vocabulary, spelling and logical thinking. Second language puzzles appeared from an early date in the history of crosswords as well. One of the earliest variants on the conventional crossword was the bilingual one in which the clues were in English and the answers in French.

However, crossword puzzles have not always been warmly invited into the classroom by second language pedagogues. In 1950, Anderson (as cited in Latorre and Baeza, 1975:46) wrote that "few if any puzzles exist which will be of any real use to the language teacher." Although several books of puzzles for L2 learners now exist, few teacher's guides recommend or even mention crosswords as a possible activity. One exception is Rivers (1981:470), who in listing "vocabulary-centered activities", gives word puzzles as the last of her suggestions: "Crosswords, acrostics and 
scrabble are useful for concentrating attention on retrieval of previously encountered words."

Some writers have attempted to give a rationale for the use of crosswords in L2 learning. Bressan (1970:94), for example, lists five benefits which can accrue from using crosswords in the language class:

1) Vocabulary building is the most obvious. Here, not only can previous knowledge be consolidated, but there can also be an acquisition of new forms and structures.

2) Orthography is also an important area, since the solution to a puzzle is based on the correct spelling of the answers.

3) Crossword puzzles can also develop and test the student's knowledge of morphology, through the use of items dealing with verb endings, prefixes, suffixes and the like.

4) Since abbreviations also occur in puzzles, this presents an opportunity to review them or introduce new ones.

5) Finally, many puzzle clues test general knowledge of a historical and cultural nature.

Omaggio (1982:518-519) has developed a "taxonomy of objectives for the development of foreign language skills". Applying this scheme to crossword puzzles, it appears that they are mainly concerned with a knowledge of specifics, usually discrete linguistic features - knowledge of vocabulary, grammatical forms and structures - although a knowledge of specific facts about a country or culture can also be involved. Most games, Omaggio states, focus primarily on the mastery of the forms of the language. Few, however, focus on developing upper-level communication skills.

Bressan's list and the lower level of Omaggio's taxonomy represent traditional views of the pedagogical value of crossword puzzles. However, while few would argue against using puzzles for these purposes, "the whole rationale of the crossword puzzle has changed: emphasis has shifted from the discovery of the answer to communication of the clue itself" (Carter, 1974:113). This changes the focus from a knowledge of specific features, as outlined by Omaggio, to the use of communicative skills. Omaggio (1982) argues that these upper-level skills can be developed with the crossword and other games. Woodeson (1982) also believes that these communicative skills are more important than the knowledge of specific vocabulary. She suggests that instead of giving students the right words to use, we should develop their independence by giving them practice in paraphrasing as a communicative strategy.

Bressan (1970) and Wolfe (1972) have attempted to classify the kinds of crossword puzzles according to the clues used. Bressan discusses two main divisions: direct-definition clues and cryptic clues. The first category includes generic, synonymic, antonymic, definitory, and descriptive clues; 
the second features anagrams, word inversions, double meanings and so on. Most second language puzzles use clues from the first category, although cryptic clues in the form of anagrams occasionally appear. Wolfe (1972) categorizes things differently in considering teacher-made crosswords in which clues are more relevant to students' needs and levels. He lists vocabulary clues which include definitions, synonymous phrases, and fill-in-the-blank items; partial answer clues in which some of the letters in the answer are provided; transformation drills; contrast of usage; picture clues; complements and opposites; and general knowledge clues. Of course, many crosswords use combinations of these, or multiple clues for each answer. To these categories can be added the single clue-multiple answer puzzle, and the bilingual crossword with the clues in the mother tongue and answers in the target language.

As mentioned above, there are many existing crossword puzzle books for ESL learners (e.g. Crowther, 1980; Hill and Popkin, 1967-1977; Jones, 1975-1979; Allen, 1956, 1970). Many are graded, with vocabularies ranging from 500 to 2,000 words, and are often designed to supplement other course books, such as graded readers. Thus, in Hill and Popkin's $A$ First Crossword Puzzle Book, since "across" is not in the lexis at this stage (although "down" is), clue headings use arrows to distinguish between horizontal and vertical ones. The kinds of clues provided are usually definitions, synonyms, pictures or are of the fill-in-the-blank type. Procedural suggestions, if made, are usually to 1 ) have students to do the crosswords individually, or 2) have them do the same crossword in pairs, or small groups, with discussion of possible answers, or 3) have them do the puzzle as a whole-class activity. Jones (1975-1979) also provides instructions on the strategies that should be used by students who have little experience with this kind of activity. This is an important point. Many students who have not been exposed to these types of puzzles, or whose culture presents them in a different way, may easily become frustrated or fed up with them, unless they are familiarized with their conventions.

However, there are more types of crosswords, and ways to use them, than it would appear from looking at these sorts of books. One type that has appeared since at least the $1950 \mathrm{~s}$ is based on the cloze reading passage. Instead of filling in the blanks in the text, the answers are written in a crossword format. This kind of variation appears in Jones, and in Hauptman and Upshur (1975). Like a standard cloze text, a crossword cloze will test general reading comprehension, prediction skills and knowledge of collocation.

Another commonly suggested procedure with crosswords is to use them as a listening activity. Lee (1982), Mollica (1978), Latorre and Baeza (1975) and Carter (1974) all suggest that either the teacher or a student 
read the clues aloud to the class. Combining this suggestion (crosswords for listening comprehension) with the previous one (crossword cloze passages), one could construct a crossword puzzle based on a cloze listening passage. The advantage of a crossword cloze (reading or listening) compared to a straightforward cloze is that students having difficulties with the text can solve some items based on previously completed ones.

Lee (1982) also suggests a team game which he calls "crossword relay". Two blank crosswords are put on the blackboard. One student from the first team and one from the second go to the blackboard and write one letter. The second student from each team then writes the second letter and so on, as they attempt to build up words. This is a competitive game much like a team scrabble.

Another intriguing kind of crossword puzzle is the single clue one. This is particularly appropriate for short thematic puzzles. Hauptman and Upshur (1975) have such puzzles for the seasons and days of the week, Cobb (1978) for numbers, and Vever (1976) suggests something similar for verb forms.

The error correction puzzle is another variant. Students are given a crossword puzzle that is partially completed with incorrect responses. They must correct and complete it. Any commercially prepared crossword can be used for their error correction exercise. The mistakes should not be too obvious, but should be based on errors one's students are likely to make.

A very productive kind of activity is offered in Frank, Rinvolucri and Berer (1982). It's called "creative crosswords". Students are provided with a completed puzzle for which they must write the corresponding clues. This kind of activity can be done with any commercially or teacher produced crossword.

Crosswords can also be used for communicative activities. Omaggio (1982) suggests an activity in which students are grouped in fours. Each student has a blank crossword puzzle and one quarter of the answers on a separate card. Each student in turn then describes the words on the card, without saying the actual word (in other words, providing the clue). The group members attempt to correctly complete that item on the puzzle. The game proceeds as each student communicates the clues for his or her words, and the group members complete the crossword. Carter (1974) puts forward a similar idea. Woodeson (1982) also suggests a communicative activity. Students are paired. Each has a version of the crossword in which a different half has been completed. The two sit back-to-back and complete their versions by giving each other verbal clues. Watcyn-Jones (1984) has adapted Woodeson's activity in his "complete the crossword". Much of the discussion so far has centered on using commercially 
prepared crosswords. However, teacher-made ones can be of value too, especially in meeting the needs and level of the students more closely. Vever (1976) puts forward the idea that teacher-made crosswords can function as a "jeu de circonstance", prepared according to the needs of the moment without advance preparation. This applies especially to short thematic puzzles, for example verb forms, as in Vever's example. Latorre and Baeza (1975) and Wolfe (1972) note that since the teacher is not a professional compiler of puzzles, strict attention to symmetry of lay-out need not be adhered to. A solution to the problem of compiling one's own puzzles may be found in Ridout's (1975-1976) puzzles, which have mostly horizontal answers with only one vertical. For those with access to a computer, there exists software for the preparation of crossword puzzles.

A linguistically productive way of approaching this activity is to have students prepare crosswords themselves. If they have already had practice in completing crosswords, in writing clues from completed puzzles, and in giving oral clues, they can then move on to making up their own. This is a good individual or small group activity. Students can be given a list of words you want them to review, or they can pick topics of themes that interest them and brainstorm to list vocabulary. Once they have a list, the next step is to put the words into the squares on a piece of graph paper, starting with the longest near the middle, either horizontally or vertically. After all the words have been placed into the grid, the next step is to write clues. Then, the grid can be traced onto a blank piece of paper. Finally the squares and clues must be numbered. After completing the task, students can exchange puzzles and try to solve them individually or in groups.

Crossword puzzles offer many possibilities for language learning. They can be used to practice and review vocabulary, orthography, morphology, grammatical structures, abbreviations and culturally-specific facts, as well as to develop communicative skills. Given their versatility and adaptability for many different purposes and levels, crossword puzzles have a legitimate place in second language teaching and learning.

\section{ENDNOTE}

1. This is a revised version of a paper given at the SPEAQ ' 86 conference in Quebec City, June 1986. I would like to thank Professor Georges Terroux of McGill University for his support and helpful comments in the preparation of an earlier version of this paper.

\section{REFERENCES}

Allen, Walter Powell. (1956). Easy crossword puzzles for people learning English. Portland, Oregon: English Language Services.

Allen, Walter Powell. (1970). More easy crossword puzzles for people learning

English. Washington, D.C.: English Language Services.

Bressan, D. (1970). Crossword puzzles in modern language teaching. Audio-Visual Language Journal 8(2):93-95. 
Carter, Thomas P. (1974). Crossword puzzles in the foreign language classroom. The Modern Language Journal 58(3):112-115.

Cobb, David. (1978). Pep 2. London: Longman.

Crowther, Jonathan. (1980). Introductory crosswords, Elementary crosswords, Intermediate crosswords, Advanced crosswords. Oxford: Oxford University Press.

Frank, Christine, Mario Rinvolucri, and Marge Berer. (1982). Challenge to think. Oxford: Oxford University Press.

Hauptman,Philip, and Jack Upshur. (1975). Fun with English. New York: Collier Macmillan.

Hill, L.A. and P.R. Popkin. (1967-1977). A first crossword puzzle book, A second..., A third..., A fourth... Oxford: Oxford University Press.

Jones, Christopher. (1975-1979). Structural crossword puzzles. Stages 1-4. Harlow: Longman.

Latorre, G., and Gloria Baeza. (1975). The construction and use of EFL crossword puzzles. English Language Teaching Journal 30(1):45-55.

Lee, W.R. (1982). Language Teaching Games and Contests. Second Edition. Oxford: Oxford University Press.

Millington, Roger. (1977). Crossword puzzles: Their history and their cult. New York: Pocket Books.

Mollica, Anthony. (1978). Mots croises. Canadian Modern Language Review 34(2):265.

Mollica, Anthony. (1981). Visual puzzles in the puzzles in the second-language classroom. Canadian Modern Language Review 37(3):583-622.

Omaggio, Alice C. (1982). Using games and interaction activities for the development of functional proficiency in a second language. Canadian Modern Language Review 38(3):517-546.

Ridout, Ronald. (1975-1976). Puzzle it out. Grades 1-5. London: Evans Brothers Ltd.

Rivers, Wilga M. (1981). Teaching foreign language skills. Chicago: University of Chicago Press.

Vever, Daniel. (1976). Jouer sans materiel. Le Francais dans le Monde 123:47-52.

Watcyn-Jones, Peter. (1984). Pair work one. Harmondsworth: Penguin.

Wolfe, David E. (1972). Teacher-made crossword puzzles. Audio-Visual Language Journal 10(3):177-181.

Woodeson, Elizabeth. (1982). Communicative crosswords. Modern English Teacher 10(2):28-29.

\section{THE AUTHOR}

James Little teaches ESL at the Canadian Forces Language School in St. Jean, Quebec. He has also taught at Concordia University and at private language schools in Ottawa and Montreal. His publishing credits include articles for TESL TALK, TESL Canada Journal, Modern English Teacher and several government publications. One of his articles has been included in the readings for a TESL course at Simon Fraser University. He is currently working on a book of crossword puzzles for ESL learners. 